\title{
Electronic and geometric structure of doped rare-gas clusters: surface, site and size effects studied with luminescence spectroscopy
}

\author{
R. von Pietrowski, ${ }^{a}$ K von Haeften, ${ }^{b}$ T. Laarmann, ${ }^{c}$ T. Möller, ${ }^{d^{*}}$ L. Museur, ${ }^{e}$ and A. V. Kanaev ${ }^{f^{*}}$ \\ ${ }^{a}$ Hamburger Synchrotronstrahlungslabor HASYLAB at Deutsches Elektronen Synchrotron DESY, Notkestr. 85, \\ 22603 Hamburg, Germany \\ ${ }^{b}$ Lehrstuhl für Physikalische Chemie II, Gebäude NC, Raum 7/33, Ruhr-Universität Bochum, Universitätsstr. 150,44780 \\ Bochum, Germany \\ ${ }^{c}$ Max-Born Institute, Max-Born str. 2 a, 12489 Berlin, Germany \\ ${ }^{d}$ Institut für Atomare Physik, Technische Universität Berlin, Hardenbergstr. 36, 10623 Berlin, Germany \\ ${ }^{e}$ Laboratoire de Physique des Lasers LPL, CNRS, Institut Galilée, Univerité Paris 13, 93430 Villetaneuse, France \\ ${ }^{f}$ Laboratoire d'Ingénierie des Matériaux et des Hautes Pressions LIMHP, CNRS, Institut Galilée, Université Paris \\ 13, 93430 Villetaneuse, France
}

\begin{abstract}
The electronic and geometric structure of rare gas clusters doped with rare-gas atoms $\mathrm{Rg}=\mathrm{Xe}, \mathrm{Kr}$ or Ar is investigated with fluorescence excitation spectroscopy in the VUV spectral range. Several absorption bands are observed in the region of the first electronic excitations of the impurity atoms, which are related to the lowest spin-orbit split atomic ${ }^{3} \mathrm{P}_{1}$ and ${ }^{1} \mathrm{P}_{1}$ states. Due to influence of surrounding atoms of the cluster, the atomic lines are shifted to the blue and broadened ("electronical cage effect"). From the known interaction potentials and the measured spectral shifts the coordination of the impurity atom in $\mathrm{Ar}_{\mathrm{N}}, \mathrm{Kr}_{\mathrm{N}}, \mathrm{Ne}_{\mathrm{N}}$ and $\mathrm{He}_{\mathrm{N}}$ could be studied in great detail. In the interior of $\mathrm{Kr}_{\mathrm{N}}$ and $\mathrm{Ar}_{\mathrm{N}}$ the Xe atoms are located in substitutional sites with 12 nearest neighbours and internuclear distances comparable to that of the host matrix. In $\mathrm{Ne}_{\mathrm{N}}$ and $\mathrm{He}_{\mathrm{N}}$ the cluster atoms (18 and 22, respectively) arrange themselves around the Xe impurity with a bondlength comparable to that of the heteronuclear dimer. The results confirm that He clusters are liquid while $\mathrm{Ne}$ clusters are solid for $\mathrm{N} \geq 300$. Smaller Ne clusters exhibit a liquid like behaviour. When doping is strong, $s m a l l ~ R g_{m}-$ clusters $\left(\mathrm{Rg}=\mathrm{Xe}, \mathrm{Kr}, \mathrm{Ar}, \mathrm{m} \leq 10^{2}\right)$ are formed in the interior sites of the host cluster made of $\mathrm{Ne}$ or He. Specific electronically excited states, assigned to interface excitons are observed. Their absorption bands appear and shift towards lower energy when the cluster size $m$ increases, according to the Frenkel exciton model. The characteristic bulk excitons appear in the spectra, only when the cluster radius exceeds the penetration depth of the interface exciton, which can be considerably larger than that in free $\operatorname{Rg}_{\mathrm{m}}$ clusters. This effect is sensitive to electron affinities of the guest and the host cluster.
\end{abstract}

(PACS) indexing codes: 36.40.-c (Atomic and molecular clusters), 36.40.Mr (Spectroscopy and geometrical structure of clusters), 73.20.-r (Electron states at surfaces and interfaces)

\section{Introduction}

In the last decade doped rare gas clusters have been used to study the properties of the clusters themselves and of the interaction between the clusters and embedded atoms and molecules [1-2]. In the course of the work it turned out that doping of clusters could be a very efficient tool in order to get information on the structure and solvation [3], the phase [4-5] and of the temperature [6] of clusters. Optical spectroscopy allows the exploration of both specific and smooth structural changes, electronic and dynamic cluster size effects. Spectroscopic studies of excited state energetics, homogeneous and inhomogeneous line broadening of doped clusters have revealed microscopic solvation, isomer structures, rigid and nonrigid configurations and isomerization dynamics. Furthermore, rare gas clusters are very useful model systems for detailed studies related to surface effects. They allow the investigation of interfaces with a shell-like geometric structure. In fact, clusters with four shells of atoms comprising about 500 atoms exhibit almost $50 \%$ of the atoms at the surface.

Electronic excitations in doped rare gas clusters fall into two main categories.

- Intravalence excitations are characterized by electronic transitions into valence orbitals. Typical examples are excitations in large molecules, e.g. aromatic organic molecules.
- Extravalence excitations are due to promotion of electrons in states, which do not take part in the chemical bonding, e.g. Rydberg states in atoms and molecules. A wealth of information has been obtained regarding intravalence excitations of molecules embedded in rare gas clusters. In this case the rare gas atoms give only rise to a weak perturbation of the excitations because the charge distribution is only slightly perturbed. As a result, the width of the absorption bands is small. In contrast, extravalence excitations considerably change the charge distribution and hence the impact on the transition energy and the absorption lineshape is large. Therefore, the energetics of the lowest extravalence states is expected to be extremely sensitive to the local environment of the guest atom, molecule, or cluster. Recently, Feifel et al. [7] have shown gradual changes of the inner valence levels in raregas clusters, from localized in Ar over the intermediate case in $\mathrm{Kr}$ to a delocalised in Xe.

$\mathrm{XeAr}_{\mathrm{N}}$ clusters have been recognized as a prototype system for the study of extravalence excitations in doped clusters. The energetics and excited state dynamics of $\mathrm{XeAr}_{\mathrm{N}}$ clusters ( $\mathrm{N}$ up to 55) was calculated several years ago [8]. Inspired by this theoretical work an experimental study was undertaken, which revealed a strong size and site dependence of the absorption bands of $\mathrm{Xe}$ doped $\mathrm{Ar}_{\mathrm{N}}$ clusters [9]. It turned out that the absorption bands of $\mathrm{Xe}$ atoms are strongly blue-shifted with respect to the lines of the free atom. Moreover, the strength of the blue shift strongly depends on the position to the Xe atom inside the argon cluster. In the related study highly excited

\footnotetext{
* corresponding authors. E-mails : kanaev@limhp.univ-paris13.fr; thomas.moeller@physik.tu-berlin.de
} 
extravalence states of $\mathrm{Xe}$ doped $\mathrm{Ar}_{\mathrm{N}}$ clusters have been investigated [10].

Numerous cluster studies have shown that excitonic absorption bands in free clusters split into electronically excited bulk and surface states [11-16]. In small free clusters composed of less then one shell around the central atom only surface excitons 1s and 1s' are observed in absorption. Bulk excitons appear, when the second shell of atoms is formed. The surface excitons can be classified as belonging to the tightly bound Frenkel type [17]. They have a very small penetration depth into the cluster, typically $\delta_{1 \mathrm{~s}} \approx 0.8 \AA[18]$ and are therefore restricted to the surface atomic layer. Bulk excitons are delocalised within the rest of the cluster volume. The extension of the experimental method $[17,19]$ allows the growth and spectroscopic analysis of small guest rare-gas $\operatorname{Rg}(2)_{\mathrm{m}}$ clusters inside large host rare-gas clusters $\operatorname{Rg}(1)_{\mathrm{N}}$. The embedded clusters acquire the temperature of the surrounding atoms, which can vary from $79 \mathrm{~K}$ (Xe) [20] down $0.4 \mathrm{~K}(\mathrm{He})$ [21]. Moreover, sizes of both guest and host cluster can be controlled. This gives a possibility of considering the electronic properties evolution from that of a single solvated atom to an embedded cluster inside the host cluster. Following both effects of the size $\mathrm{m}$ and $\mathrm{N}$ could monitor build up of the electronic and geometric structures of the cluster.

The present work is an extension of our previous studies of rare gas clusters made of $\operatorname{Rg}(1)=\mathrm{Kr}, \mathrm{Ar}, \mathrm{Ne}$ and $\mathrm{He}$ atoms and doped with rare gas atoms $\operatorname{Rg}(2)=\mathrm{Xe}, \mathrm{Kr}$ or Ar. Changing the doping conditions single embedded atom $\operatorname{Rg}(2)$ as well as small embedded clusters $\operatorname{Rg}(2)_{\mathrm{m}}$ are considered. The study focuses on the first extra valence excitation in the doped clusters. Fluorescence excitation spectroscopy with synchrotron radiation (SR) was used for monitoring the impurity absorption. Substantial differences in the excitonic spectra were observed for different pairs of rare-gases $\operatorname{Rg}(1)_{\mathrm{N}}-\operatorname{Rg}(2)_{\mathrm{m}}$.

In case of the isolated atom $(\mathrm{m}=1)$, strong $\mathrm{N}$-size and site effects manifest themselves, which depend on the rigidity of the host material. He is a special case since the clusters are fluid. In order to get deeper insight into experimental results some simple molecular dynamics simulations were performed. In particular, coordination number and the local structure around the impurity atom are derived this way. Furthermore, internuclear separation between this atom and the neighbouring atoms of the cluster could be obtained. In case of the embedded cluster $(m>1)$, new interface excitons appear. Their spectral lineshape changes with their size $m$ according to the Frenkel exciton model. We show that the interface exciton can penetrate into the guest cluster volume on a substantial length of several interatomic distances. This size effect depends on both electronic affinities of the host and the guest materials.

The paper is organized in the following way. The experimental method is described in next section. In the section Results we firstly discuss the case of a single embedded $\mathrm{Xe}, \mathrm{Kr}$ or $\mathrm{Ar}$ atom inside $\mathrm{Kr}, \mathrm{Ar}, \mathrm{Ne}$ and $\mathrm{He}$ clusters. The case of the small embedded $\mathrm{Xe}, \mathrm{Kr}$ or Ar clusters inside large $\mathrm{Ne}$ and $\mathrm{He}$ host clusters is presented afterwards. In the conclusion we resume the main results of these studies.

\section{Experimental}

The measurements were performed at the experimental setup CLULU at the beamline SUPERLUMI [22] at the Hamburger Synchrotronstrahlungslabor HASYLAB. A detailed description of the experimental setup is given in [23]. Doped clusters are prepared either in a nozzle expansion of a gas mixture or by a pick-up technique were the cluster beam is crossed with an atomic beam. Conical nozzles with the following diameters and opening angles $(2 \theta)$ were used in the coexpansion experiments: $0.1 \mathrm{~mm} 30^{\circ}, 0.2 \mathrm{~mm} 30^{\circ}$ and $0.3 \mathrm{~mm} 16^{\circ}$. For a given nozzle and gas the cluster size depends on the stagnation pressures $p_{0}$ and the nozzle temperatures $\mathrm{T}_{0}$. A scaling law has been proposed by Hagena and Obert [24] and Hagena [25], which is valid for all monoatomic supersonic nozzle expansions. In order to compare cluster beams a parameter $\Gamma^{*}$ is introduced which characterizes the degree of condensation in the beam and the mean cluster size. $\Gamma^{*}$ can be calculated by following equation (1a):

$$
\Gamma^{*}=\mathrm{K}_{\mathrm{ch}} \cdot \mathrm{P}_{0} \cdot \mathrm{d}_{\mathrm{eq}}{ }^{0.85} / \mathrm{T}_{0}^{2.2875}
$$

Here $K_{c h}$ is a gas characteristic constant, $d_{e q}$ (in $\mu \mathrm{m}$ ) the equivalent nozzle diameter, and $\mathrm{p}_{0}$ and $\mathrm{T}_{0}$ are respectively in mbar and in $\mathrm{K}$. The relationship between $\Gamma^{*}$ and the mean cluster size $<\mathrm{N}>$ has been derived from mass spectra [23] and, as discussed in Ref. [26], can be approximated by the expressions:

$$
<\mathrm{N}>=38.4 \cdot\left(\Gamma^{*} / 1000\right)^{1.64}
$$

for relatively small clusters $\left(350 \leq \Gamma^{*} \leq 1800\right)$ and

$$
<\mathrm{N}>=33 \cdot\left(\Gamma^{*} / 1000\right)^{2.35}
$$

for larger clusters $\left(\Gamma^{*} \geq 1800\right)$. For all spectra in this wor mean cluster size has been derived by using Eqs 1(a-c). The cluster size is generally described by a lognormal distribution [27]. The width of this cluster size distribution $\Delta \mathrm{N}$ is rather large and it is close to the mean cluster size $<\mathrm{N}>$. Single-atoms doped clusters were also prepared by expanding gas mixtures containing $0.001 \%$ to $0.03 \%$ of impurity atoms.

The size of embedded $\mathrm{Rg}_{\mathrm{m}}$ clusters in pick-up experiments is governed by the Poisson distribution. It has been obtained by a comparison between the spectral lineshapes related to the lowest exciton absorption band of $\mathrm{Ar}_{\mathrm{m}}$ inside large neon clusters as it is explained in Ref. [28]. The method is based on theoretical and experimental work by Lewerenz at al. [29] and recent experiments by Laarmann at al. [17], who has shown that the absorption lineshape of tightly bound excitons in $\mathrm{Ar}_{\mathrm{m}}$ clusters is sensitive to their size $m$. By comparing VUV-fluorescence excitation spectra of $\mathrm{Ne}_{\mathrm{N}} \mathrm{Ar}_{\mathrm{m}}$ clusters in the range of $12.4 \mathrm{eV}$ measured in the given experimental geometry with those from [17], one can obtain a relation between the cross-jet pressure and the average number of embedded atoms. Since the probability for a Ne cluster to pick-up atoms is mainly depending on the $\mathrm{Ne}$ cluster size and the average cross-jet particle density along the beam axes, the calibration can be used in case of arbitrary raregas doping.

The temperature of rare-gas cluster produced in neat gas expansion is reported in Refs [20-21]. The clusters produced in seeded beam expansions may be colder. However, when clusters are formed out the 'seed' gas and atoms of the small admixture of a few percent or less are embedded in the clusters, they are not colder than in neat gas expansion. According to theoretical simulation [30-32], $\mathrm{Ar}_{\mathrm{N}}$ clusters of sizes $\mathrm{N}>50$ are expected to be solid. We are not aware of any similar study on Kr clusters, but would expect that $\mathrm{Kr}$ clusters are also solid. Ne clusters is a special case because of their strong quantum nature. Large neon clusters are solid, but very soft solids. Since the temperature is not known sufficiently precisely, a real meaningful comparison with simulations is not feasible.

Since the photoabsorption of rare gas cluster beams is very weak, the information on the electronically excited states can be obtained by recording fluorescence excitation spectra. This method can be applied to samples provided their fluorescence yield or sensitivity of the registration equipment is high enough. It is based on recording fluorescence intensity from the sample as a function of the excitation wavelength (or energy). The observed spectrum is a convolution of the absorption coefficient and the energy transfer process efficiency. Moreover, in rare gas clusters excited below the ionisation threshold these spectra represent the absorption spectra because the internal energy conversion resulting to fluorescence is almost $100 \%$. Despite of the high cluster beam transparency, the exciton absorption of pure as well as doped rare gas clusters can be measured in such way.

Monochromatised synchrotron radiation (SR) in the VUV spectral range (band pass $0.25 \mathrm{~nm}$ corresponding to $14 \mathrm{meV}$ at 8 $\mathrm{eV}$ ) is focussed on to the doped cluster beam for excitation. Fluorescence excitation spectra in the VUV-UV $(\lambda \leq 300 \mathrm{~nm})$ and in the UV-visible-IR $(200 \mathrm{~nm} \leq \lambda \leq 900 \mathrm{~nm})$ were recorded by two photomultipliers with $\mathrm{CsI}$ and $\mathrm{GaAs}(\mathrm{Cs})$ photocathodes, 
respectively. The background pressure was kept below $10^{-3} \mathrm{mbar}$ during the experiments.

\section{Results and Discussion}

\subsection{Single embedded atom}

\subsection{1. $\operatorname{XeAr}_{N}$}

$\mathrm{XeAr}_{\mathrm{N}}$ clusters can be seen as a model system of doped rare gas clusters. They have already been studied in great detail [9-10,3334] and show a variety of interesting features. Fluorescence excitation spectra of $\mathrm{XeAr}_{\mathrm{N}}$ clusters are shown in Fig. 1 for different mean cluster sizes from $\langle\mathrm{N}\rangle=2$ to $\langle\mathrm{N}\rangle=5000$. In the energy range of the first electronic excitations of free Xe atoms, depending on the cluster size, five absorption bands appear. As discussed in [9] and [10] these bands can be assigned to the $6 \mathrm{~s}[3 / 2]_{1} \leftarrow 5 \mathrm{p}$ transition of Xe. Due to the overlap between the electron of the excited Xe atom with electrons of the surrounding atoms of the cluster these transitions are shifted to the blue. The energy shift is related to the number of nearest neighbours and the overlap between the electron clouds, which is related to the internuclear separation. Thus, it contains information on possible sites of $\mathrm{Xe}$ atom in the cluster. In a detailed theoretical study using molecular dynamics (MD) simulations Goldberg, Heidenreich and Jortner [33] investigated the electronic structure

Table 1 Parameters of the Xe-Rg differential potential derived from the potential curves of the ground [35] and first excited state [36].

\begin{tabular}{|c|c|c|c|c|}
\hline $\mathrm{Rg}$ & $\mathrm{Kr}^{\mathrm{a}}$ & $\mathrm{Ar}^{\mathrm{b}}$ & $\mathrm{Ne}^{\mathrm{b}}$ & $\mathrm{He}^{\mathrm{b}}$ \\
\hline$a[\mathrm{eV}]$ & 400000 & 6200 & 90 & 190 \\
\hline$\gamma\left[\AA^{-1}\right]$ & 3.94 & 3.05 & 2.06 & 2.21 \\
\hline
\end{tabular}
${ }^{a}$ Ref. [5] ${ }^{\mathrm{b}}$ Ref. [33]

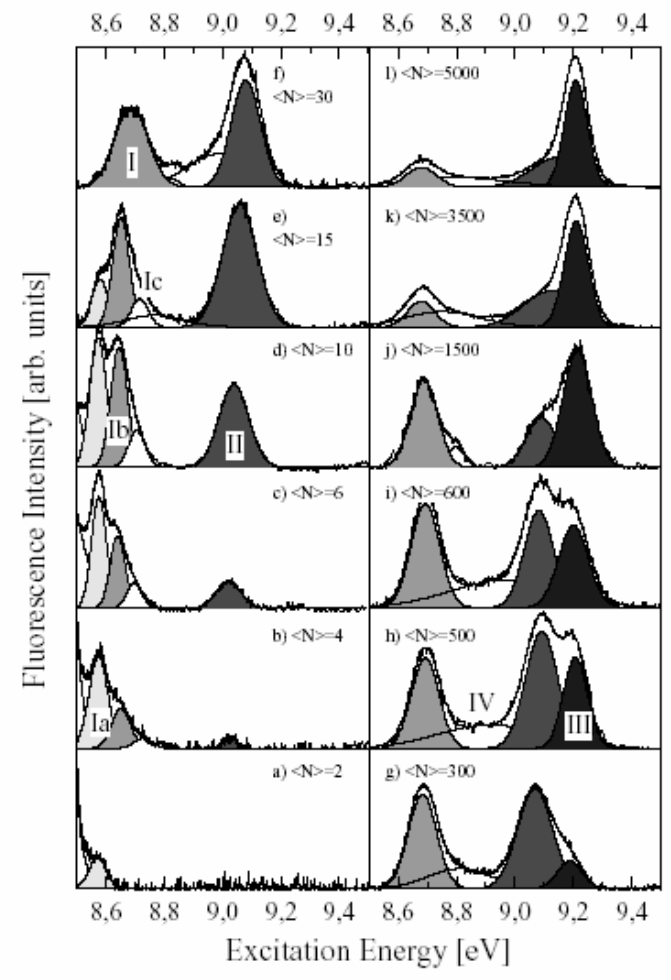

Fig. 1 Fluorescence excitation spectra of $\mathrm{XeAr}_{\mathrm{N}}$ clusters (coexpansion $0.01 \% \mathrm{Xe}$ in $\mathrm{Ar}$ ) for different cluster sizes $<\mathrm{N}>$.
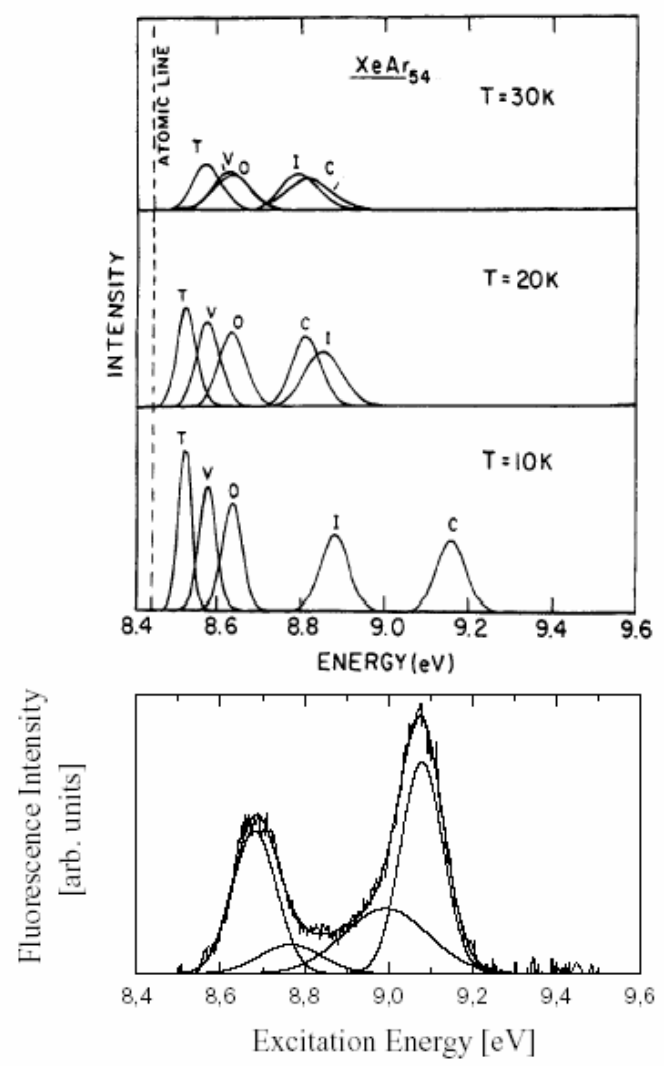

Fig. 2 Comparison between calculated absorption $(N=54)$ [33] and measured fluorescence excitation $(<\mathrm{N}>=30)$. The bands are labelled according to Table 2 .

of $\mathrm{XeAr}_{\mathrm{N}}$ clusters. With the potential curves of the heteronuclear dimer they have derived the dependence of the energy shift $\Delta \mathrm{E}$ from the number $\mathrm{N}_{\mathrm{NN}}$ and the distance $\mathrm{r}_{\mathrm{NN}}$ of the nearest neighbours of the $\mathrm{Xe}$ atom in $\mathrm{XeAr}_{\mathrm{N}}$ clusters:

$$
\Delta \mathrm{E}=a \cdot \mathrm{N}_{\mathrm{NN}} \cdot \exp \left(-\gamma \cdot \mathrm{r}_{\mathrm{NN}}\right)
$$

This equation holds for the doped rare gas clusters if the internuclear distances between an impurity atom and its nearest cluster atoms are close to the equilibrium distance of the ground state potential. The differential potential can be fitted with Eq. (2) and the values $a$ and $\gamma$ are listed in Table 1 for $r_{\mathrm{NN}}$ being within $\pm 10 \%$ of the ground-state equilibrium distance. Using Eq. (2) one can assign the absorption bands of Xe doped Ar clusters to Xe atoms sitting in different sites in the cluster. In the following we like to discuss the assignment of the absorption bands to different sites in great detail. This is of importance because the first assignment based on experimental results [9] disagrees considerably with that given in the theoretical work by Goldberg et al. [33].

It is not possible to assign the bands just from their measured energy shift $\Delta \mathrm{E}$ of one cluster size because $\Delta \mathrm{E}$ is a function of $\mathrm{N}_{\mathrm{NN}}$ and $\mathrm{r}_{\mathrm{NN}}$. Therefore, one has to make reasonable assumptions about the number of nearest neighbours. We will compare the measured spectra with that from MD-calculations by Goldberg et al. [33], where the numbers $\mathrm{N}_{\mathrm{NN}}$ are given. The results of these calculations for $\mathrm{XeAr}_{54}$ clusters are presented in the Fig. 2. They are shown for different cluster temperatures and compared with an absorption spectrum measured for XeAr clusters containing in average $<\mathrm{N}>=30$ atoms. However, we like to point out that the calculated spectra are very sensitive to the temperature of the clusters. In view of the results from electron diffraction giving a temperature of argon clusters of $\sim 30 \mathrm{~K}$ [20], we use for comparison the calculated spectra for $\mathrm{T}=30 \mathrm{~K}$. We have not recorded spectra with exactly the same cluster sizes as used in the calculations but the variations in the measured spectra for clusters sizes between 30 and 100 are only small. 
Table 2 Equivalent sites and number of nearest neighbours $\left(\mathrm{N}_{\mathrm{NN}}\right)$ in $\mathrm{XeAr}_{54}$ and $\mathrm{XeAr}_{146}$ clusters considered in the perfect icosahedral structure with respectively $2^{\text {nd }}$ or $3^{\text {rd }}$ shells closed [33].

\begin{tabular}{|c|c|c|}
\hline \multicolumn{3}{|c|}{} \\
\hline cluster sites & Number of equivalent sites & $\mathrm{N}_{\mathrm{NN}}$ \\
\hline $\mathrm{XeAr}_{54}-$ central (c) & 1 & 12 \\
\hline inner edge (i) & 12 & 12 \\
\hline outer edge (o) & 30 & 8 \\
\hline vertex (v) & 12 & 6 \\
\hline $\mathrm{XeAr}_{146}-$ central & 1 & 12 \\
\hline 1 & 12 & 12 \\
\hline 2 & 30 & 12 \\
\hline 3 & 12 & 12 \\
\hline $4^{a}$ & 20 & 9 \\
\hline $5^{a}$ & 60 & 8 \\
\hline $6^{a}$ & 12 & 6 \\
\hline
\end{tabular}

${ }^{a}$ surface sites

The numbers of equivalent sites and their numbers of the nearest neighbours in $\mathrm{XeAr}_{54} \mathrm{XeAr}_{146}$ clusters are listed in Table 2. As one can see from this table, clusters containing more than 12 atoms can accommodate impurity atoms in interior sites. Atoms in surface sites are characterised by lower coordination numbers, e.g. 3-9 in rare gas clusters, depending on the location (corner, edge face etc.).

In icosahedra with the second shell closed represented by $\mathrm{XeAr}_{54}$ cluster there are four distinguishable sites (see Table 2). If one considers the statistical weight number of atoms in these sites, two most significant absorption bands observed at $8.7 \mathrm{eV}$ (I) and $9.1 \mathrm{eV}$ (II) (see Fig. 2b) could be respectively assigned to outer and inner edge. Using multiple Gauss fitting procedure, the band I has been decomposed into Ia, Ib and Ic subbands that is shown in Fig. 1. Moreover, the band II contains a shoulder at $9.19 \mathrm{eV}$, labelled by us the band III and which grows up for large cluster sizes. In view of the large spectral shift these both bands II and III have been assigned to interior sites.

For the outer edge site (band "o" in Fig. 2) the energy shift is in good agreement with that from the MD-simulations by Goldberg et al. [33]. On the other hand, in contrast to the theoretical predictions for the central position of Xe atom (band "c"), there is only a weak absorption in the energy region from $8.8 \mathrm{eV}$ to 8.9 $\mathrm{eV}$. The discrepancy with the observed position of the inner edge band II (in our assignment) amounts for $0.3 \mathrm{eV}$. This tendency is also kept for bigger clusters. The theoretical analysis of the $\mathrm{XeAr}_{146}$ cluster has shown that their spectral bands originate from seven different sites (Table 2): three surface sites group are around $8.6 \mathrm{eV}$ and four interior sites spread from $8.8 \mathrm{eV}$ to nearly $9.4 \mathrm{eV}$. However, the spectrum of $\langle\mathrm{N}\rangle=300$ clusters in Fig. 1 does not agree these predictions.

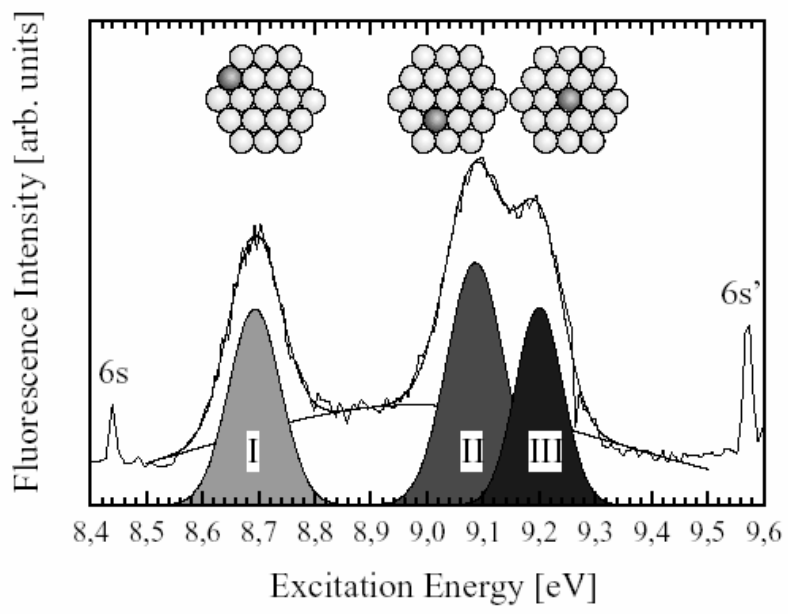

Fig. 3 Assignment of the absorption bands I, II, and III to different sites of single $\mathrm{Xe}$ atom in $\mathrm{Ar}_{\mathrm{N}}$ cluster.
Table 3 Results of analysis of $\mathrm{XeAr}_{\mathrm{N}}$ clusters: average spectral shift $\Delta \mathrm{E}$, number of nearest neighbours $\mathrm{N}_{\mathrm{NN}}$, average internuclear separation $\left\langle\mathrm{r}_{\mathrm{NN}}\right\rangle$ calculated with Eq. (2). $\Delta \mathrm{r}_{\mathrm{NN}}$ (fwhm) is obtained from Eq. (2) assuming the error bar of the absorption band energy is $20 \%$ of the bandwidth and $\Delta \mathrm{r}_{\mathrm{NN}}$ (size) is obtained assuming the cluster size variation of $20 \%$.

\begin{tabular}{|c|c|c|c|c|c|}
\hline Band & $\Delta \mathrm{E}, \mathrm{meV}$ & $\mathrm{N}_{\mathrm{NN}}$ & $\left\langle\mathrm{r}_{\mathrm{NN}}>, \AA\right.$ & $\Delta \mathrm{r}_{\mathrm{NN}}(\mathrm{fwhm})$ & $\Delta \mathrm{r}_{\mathrm{NN}}($ size $)$ \\
\hline $\mathrm{Ia}$ & 137 & 6 & 4.10 & 0.03 & 0.02 \\
\hline $\mathrm{Ib}$ & 215 & 8 & 4.05 & 0.02 & 0.006 \\
\hline $\mathrm{Ic}$ & 278 & 9 & 4.00 & 0.02 & 0.01 \\
\hline $\mathrm{II}$ & 635 & 12 & 3.827 & 0.01 & 0.007 \\
\hline $\mathrm{III}$ & 771 & 12 & 3.763 & 0.009 & - \\
\hline $\mathrm{Ar}_{2}$ & & & $3.82^{\mathrm{a}}$ & & \\
\hline $\mathrm{Ar}$ solid & & & $3.75^{\mathrm{a}}$ & & \\
\hline $\mathrm{Xe}-\mathrm{Ar}$ & & & $4.08^{\mathrm{a}}$ & & \\
\hline
\end{tabular}

${ }^{a}$ Ref. [35]

As we have already remarked, the calculations by Goldberg et al. [33] have shown that the band positions depend on the cluster temperature. E.g. the absorption energy of Xe atoms on the central site in $\mathrm{XeAr}_{54}$ cluster shifts by almost $0.4 \mathrm{eV}$ to lower energies as temperature grows from $10 \mathrm{~K}$ to $30 \mathrm{~K}$. The shift of other bands of $\mathrm{XeAr}_{54}$ as well as the bands of $\mathrm{XeAr}_{146}$ clusters is also appreciable though smaller. Assuming the temperature is the key factor for the band position, the temperature of the clusters in our experiments could be estimated. For relatively larger clusters containing more than 300 argon atoms the temperature is between $30 \mathrm{~K}$ and $40 \mathrm{~K}$, which is in agreement with that given for free argon clusters by Farges et al. [20]. For smaller clusters the temperature would be considerably lower, $\sim 10 \mathrm{~K}$. This seems not to be a realistic supposition.

In order to access more information about the temperature dependence, we have performed measurement with $\mathrm{XeAr}_{\mathrm{N}}$ clusters seeded in large $\mathrm{Ne}$ clusters (by coexpansion of $0.001 \% \mathrm{Xe} / 10 \% \mathrm{Ar} / 90 \% \mathrm{Ne}$ gas mixture) and by an aggregation

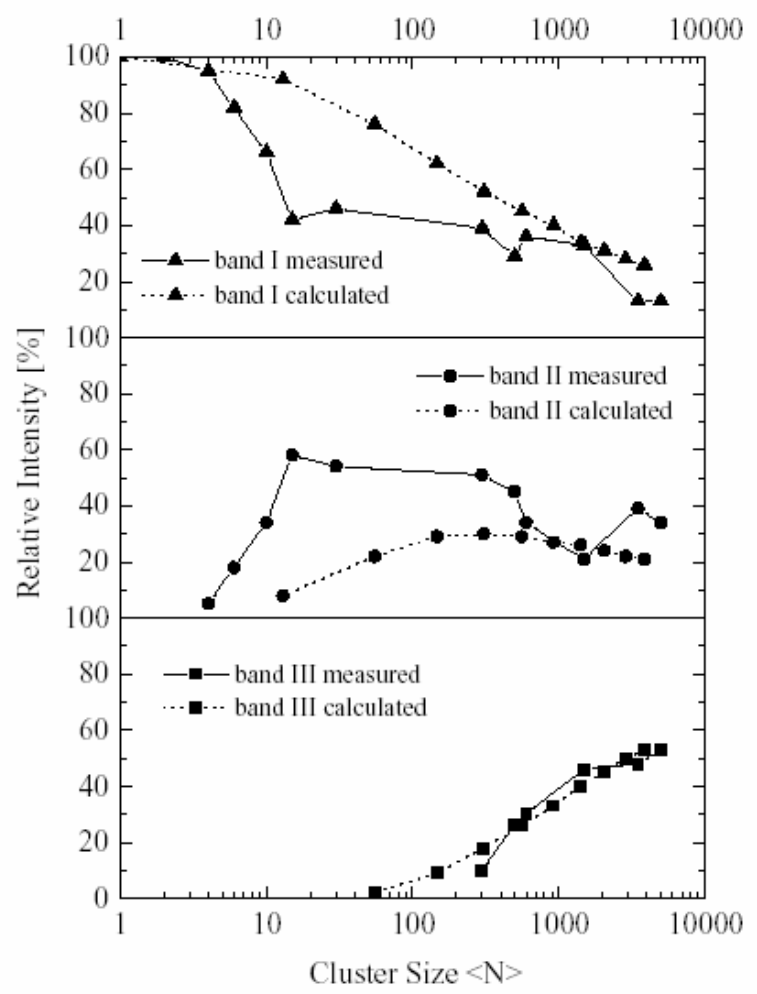

Fig. 4 Comparison between the measured and calculated relative intensities of the $\mathrm{XeAr}_{\mathrm{N}}$ absorption bands. 
of $\mathrm{Xe}$ and $\mathrm{Ar}$ atoms inside He clusters using the multiple pick-up doping technique. The $\mathrm{XeAr}_{\mathrm{N}}$ cluster temperature in these experiments was considered equal to that of the large host clusters made of neon and helium. The excitation spectra of the solute $\mathrm{XeAr}_{\mathrm{N}}$ clusters in helium $(\mathrm{T}=0.4 \mathrm{~K}$ [21]) and that of $\mathrm{XeAr}_{\mathrm{N}}$ clusters in neon $(\mathrm{T}=10 \mathrm{~K}[20])$ are found very similar to that of free $\mathrm{XeAr}_{\mathrm{N}}$ clusters from Fig. $1\left(10^{2} \leq \mathrm{N} \leq 10^{3}\right)$. These results give no evidence for strong temperature dependence in the range of $0.4-30 \mathrm{~K}$

Complimentary information concerning the assignment of the absorption bands has been obtained from measurements with an atomic crossjet. In these experiments the condensation of argon clusters is achieved before arriving in the crossjet region and $\mathrm{Xe}$ atoms land on the surface of $\mathrm{Ar}_{\mathrm{N}}$. In this case surface sites are preferentially populated and the bands $\mathrm{Ia}, \mathrm{Ib}$ and Ic, related to the surface position of xenon atoms, are expected to dominate the absorption spectra. The measured spectra of clusters with $<\mathrm{N}>=150$ atoms and a crossjet pressure of 2 mbar indeed agreed this prediction. However, in smaller clusters this was not valid and bulk site are also occupied. Apparently, the energy that is released on the impact of the Xe atom was sufficiently high that small argon clusters melt and Xe atoms solvates in the interior. For larger crossjet pressures ( $\geq 10$ mbar) more than one Xe atom is built into the clusters and new absorption bands from solvated dimers and small xenon clusters have been observed in the spectral region between 8.7 and $9.1 \mathrm{eV}$.

Based on our experimental results and the MD-simulations [33] we propose the following assignment, which is illustrated in Fig. 3. The bands Ia, Ib and Ic (merged into the band I) are from Xe atoms in surface sites with 6,8 and 9 nearest neighbours, while the bands II and III are from Xe atoms in the interior of the clusters with 12 nearest neighbours each but slightly different internuclear distances. More precisely, we suggest that band II is due to Xe atoms one layer below the cluster surface, and band III is due to Xe atoms at least two layers below the surface. Within the experimental error bar the band III lies at the same position as the absorption band of Xe-doped Ar solids [37].

The disagreement between the predicted and measured positions of bands II and III can be accommodated adjusting the bond length. Indeed, using the pair potentials from Table 1 and the number of nearest neighbours, the internuclear distance $r_{\mathrm{NN}}$ entering Eq. (2) can be calculated from the measured energy shift. The result is shown in Table 3 and compared with the bondlength of $\mathrm{Ar}_{2}, \mathrm{XeAr}$ dimer and solid $\mathrm{Ar}$ lattice. For the surface sites $\mathrm{Ia}, \mathrm{Ib}$ and Ic the internuclear separation is found close to the one for the XeAr dimer. On the other hand, for the two interior sites II and III the internuclear distances are obtained close to that of pure argon solid. Moreover, relative position of the bands II and III indicate that deeper lying sites undergo stronger compression. The compression of xenon atom inside the argon cluster amounts to $0.25 \AA$ (II sites) and $0.32 \AA$ (III sites). This seems reasonable, as lattice compression about several percents can be observed in small clusters as reported by Wang and Herron [38]. We note however that the two body difference potentials between rare-gas atoms $\mathrm{Ar}-\mathrm{Ar}$ and $\mathrm{Xe}-\mathrm{Ar}$ entering into the calculation, are not sufficient precise, especially in the inharmonic parts, which may also contribute in the discrepancies between the calculated and measured spectra.

Finally, we like to point out that the overall picture of surface and interior sites is well established. Furthermore, the observed linewidths are in good agreement with the calculated ones. This is particularly true for "large clusters" were the agreement between experimental and theoretical data is already rather good. The dependence of relative intensities of different absorption bands on the cluster size is shown in Fig. 4. All surface bands have been summed up to one band I. The calculated intensities of these bands, assuming equal population probabilities of the corresponding sites in closed-shell icosahedra, satisfactory

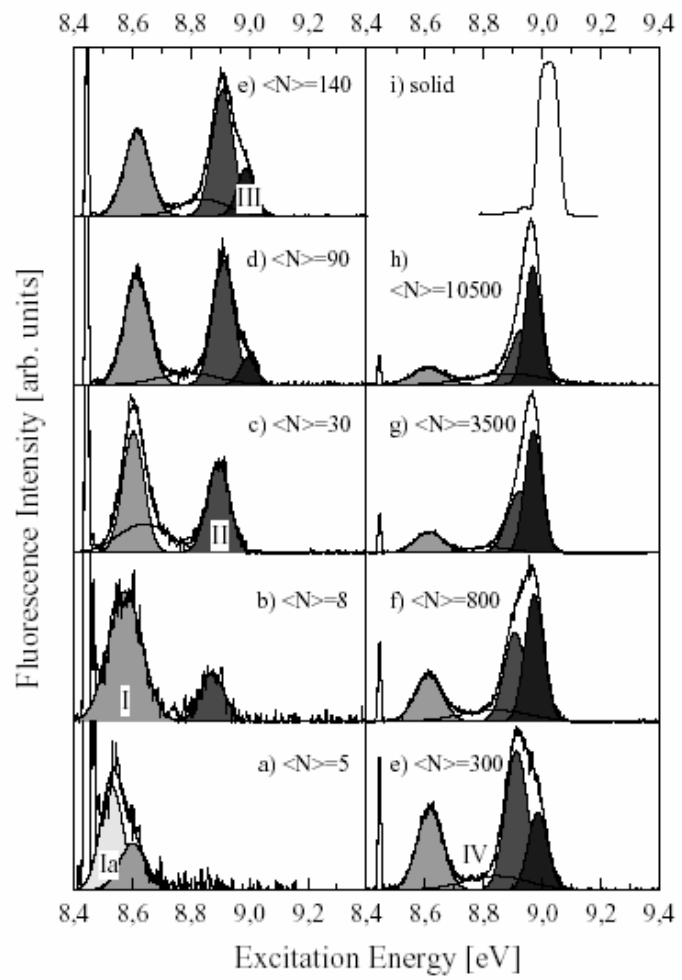

Fig. 5 Fluorescence excitation spectra of $\mathrm{XeKr}_{\mathrm{N}}$ clusters (coexpansion $0.01 \% \mathrm{Xe}$ in $\mathrm{Kr}$ ) for different cluster sizes $<\mathrm{N}>$.

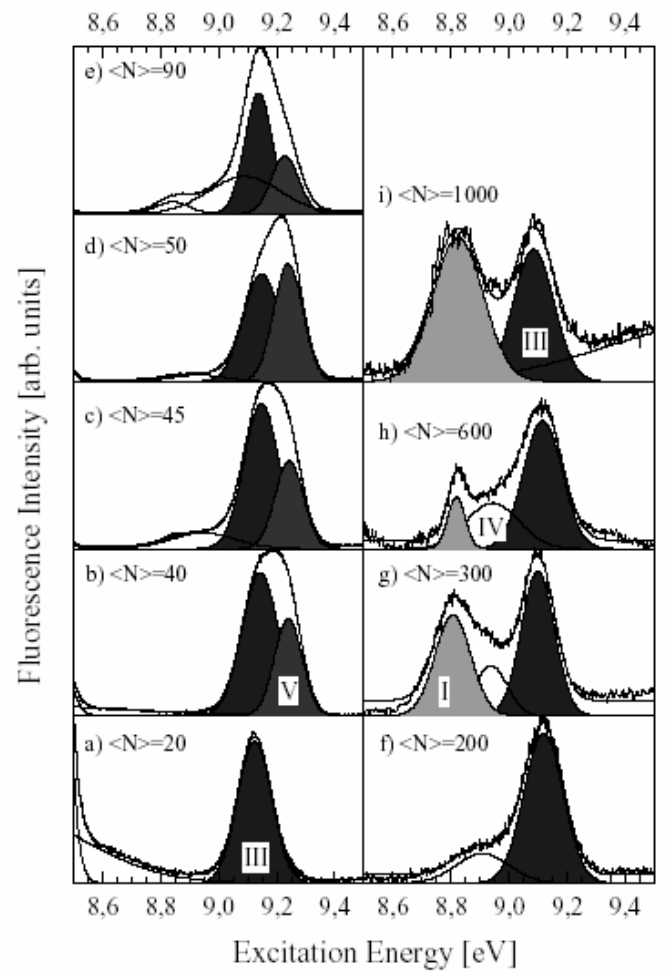

Fig. 6 Fluorescence excitation spectra of $\mathrm{XeNe}_{\mathrm{N}}$ clusters (coexpansion $0.001-0.003 \% \mathrm{Xe}$ in $\mathrm{Ne}$ ) for different cluster sizes $<\mathrm{N}>$. 
follow the measured intensities. E.g. the relative intensity of the surface sites I decreases continuously with increasing cluster size. However, in the range from $\langle\mathrm{N}\rangle=10$ to $\langle\mathrm{N}\rangle=300$ the calculated curve is well above the measured one. In the same time, the band II due to Xe atoms one monolayer below the surface intensifies in this cluster size range. This is a strong indication that $\mathrm{Xe}$ atoms dive from the surface into the interior of the clusters, in agreement with theoretical predictions by Perera et al. [39]. The band III due to Xe atoms deep inside the clusters becomes significant for sizes above 300 at./cluster. For these cluster sizes the band intensities follow the theoretical curves. This is a strong indication that $\mathrm{Xe}$ atoms are built into the cluster sites statistically.

According to Ref. [32] the total binding energy for $\mathrm{Ar}_{146}$ clusters with $\mathrm{Xe}$ atoms in different interior sites with 12 nearest neighbours varies by up to $100 \mathrm{meV}$ that is larger than $\mathrm{kT}$ at 30 $\mathrm{K}$. Surprisingly, the Xe in the central site is quite energetically quite unfavourable. This behaviour becomes clear remembering that Xe atoms do not fit into the cluster. As a result, the whole $\mathrm{Ar}$ cluster gets somewhat expanded and bonds get weaker. These calculations were done assuming $\mathrm{T}=0$. At a temperature of $30-40 \mathrm{~K}$ the cluster expands further due to the inharmonic potential and the differences in energy become smaller [3]. The experimentally observed statistical distribution over different sites indicates that the population is more controlled by the growth rate than the energetics.

In the following, we will use the band notion of $\mathrm{XeAr}_{\mathrm{N}}$ clusters by discussing results obtained with different doped $\operatorname{Rg}(2) \operatorname{Rg}(1)_{\mathrm{N}}$ clusters.

\subsection{2. $\mathrm{XeKr}_{\mathrm{N}}$}

In order to understand the role of the host material on the electronic structure and geometry $\mathrm{Xe}$-doped $\mathrm{Kr}_{\mathrm{N}}$ clusters have been studied. Since Xe-Ar and $\mathrm{Xe}-\mathrm{Kr}$ pair potentials and the geometrical properties of solid Ar and $\mathrm{Kr}$ (lattice constant, etc) are rather similar, the $\mathrm{N}$-size behaviour of the absorption spectra of $\mathrm{XeKr}_{\mathrm{N}}$ clusters is expected to agree the above discussion.

A series of fluorescence excitation spectra of $\mathrm{XeKr}_{\mathrm{N}}$ clusters for different cluster sizes from $<\mathrm{N}>=5$ to $<\mathrm{N}>10500$ are presented in Fig. 5. Three dominant absorption bands have been assigned: (i) absorption band at $8.98 \mathrm{eV}$ is due to $\mathrm{Xe}$ atoms deep inside the $\mathrm{Kr}_{\mathrm{N}}$ clusters (band III), (ii) absorption band at $8.9 \mathrm{eV}$ is due to $\mathrm{Xe}$ atom one monolayer below the surface (band II), and (iii) absorption band at $8.6 \mathrm{eV}$ is due to $\mathrm{Xe}$ atoms at the cluster surface (band I). We remark, that because different surface absorption bands overlap, only two subbands may be resolved by using the multiple Gauss fit (one is labelled as Ia). Moreover, even in the largest prepared $\mathrm{Kr}_{\mathrm{N}}$ clusters the peak position of the absorption band of the $\mathrm{Xe}$ atoms in the deep interior sites (band III) is considerably shifted relative to that of the bulk Xe atom in the solid krypton lattice [40]. The origin of this discrepancy is not yet understood.

Using Eq. (2) and Table 2 and the measured spectral shifts $\Delta \mathrm{E}$ we have calculated the internuclear distances between Xe atom and surrounding $\mathrm{Kr}$ atoms at different sites of the clusters. These results are shown in Table 4 and exhibits the same general trends as observed in $\mathrm{XeAr}_{\mathrm{N}}$ clusters. The $\mathrm{Xe}$ atom in the interior sites is compressed by approximately $0.11 \AA$ (site II) and $0.14 \AA$ (deeper site III): the $\mathrm{Xe}-\mathrm{Kr}$ interatomic distance is found closer to that of $\mathrm{Kr}_{2}$ dimer than of $\mathrm{XeKr}$. Moreover, no doped atom compression is found in the surface sites. The intensity variations of the different absorption bands with the cluster size $\mathrm{N}$ are also similar to that observed in $\mathrm{XeAr}_{\mathrm{N}}$ clusters.

\subsubsection{Comparison between $\mathrm{XeAr}_{\mathrm{N}}$ and $\mathrm{XeKr}_{\mathrm{N}}$ clusters}

$\mathrm{Xe}$ atoms are built into substitutional sites of the $\mathrm{Ar}_{\mathrm{N}}$ and $\mathrm{Kr}_{\mathrm{N}}$ clusters. Our estimations show that the doped atoms in the interior sites are considerably compressed by the surrounding atoms. This results in a substantially smaller internuclear separation between $\mathrm{Xe}$ and $\mathrm{Ar}$ or $\mathrm{Kr}$ than in the equilibrium one of corresponding heteronuclear dimmers $\mathrm{Xe}-\mathrm{Ar}$ and $\mathrm{Xe}-\mathrm{Kr}$. This distance approaches the equilibrium interatomic distance of the

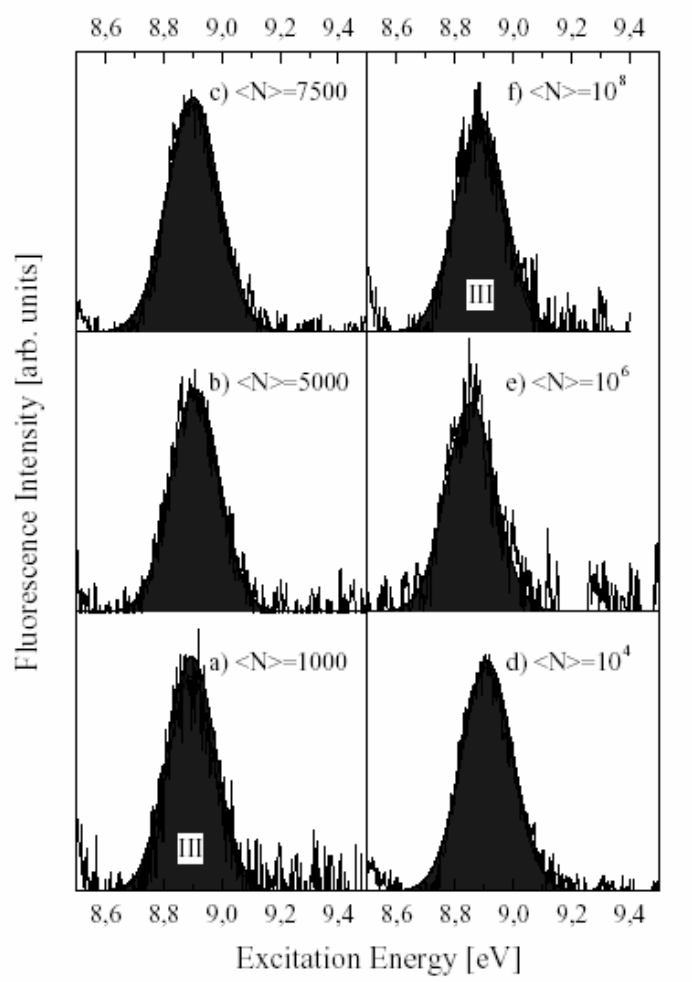

Fig. 7 Fluorescence excitation spectra of $\mathrm{XeHe}_{\mathrm{N}}$ clusters prepared by pick-up technique for different cluster sizes $<\mathrm{N}>$.

pure matrix. Moreover, the site compression is found stronger in Ar lattice than in $\mathrm{Kr}$ one. This may be related to a larger mismatch between the sizes of the impurity and lattice atoms in the first case. On the other hand, no appreciable compression of the impurity is observed in the surface sites, where the internuclear distance is very similar to that of the corresponding heteronuclear dimer. Relative strengths of the absorption bands generally reflect the statistical weight distribution of the sites available for doping. However, inside the small clusters containing less than 300 atoms the first subsurface site (band II), which is one monolayer below the surface, has higher occupancy than the surface substitutional sites. No Xe atoms on the top of the cluster could be identified in $\mathrm{XeAr}_{\mathrm{N}}$ and $\mathrm{XeKr}_{\mathrm{N}}$ clusters.

\subsection{4. $\mathrm{XeNe}_{\mathrm{N}}$}

Fluorescence excitation spectra of $\mathrm{XeNe}_{\mathrm{N}}$ clusters are presented in Fig. 6 [5]. Three absorption bands have been resolved and identified according to the model approach described for $\mathrm{XeAr}_{\mathrm{N}}$ clusters. The strength of these bands shows an unusual variation with the cluster size, which considerably differs from that observed in $\mathrm{XeAr}_{\mathrm{N}} \mathrm{XeKr}_{\mathrm{N}}$ clusters. The band III at $9.1 \mathrm{eV}$ has been ascribed to $\mathrm{Xe}$ atoms in the interior of the Ne clusters (below 1 atomic layer under the surface). It dominates spectra for all cluster sizes from very small containing 20 atoms and until the largest prepared of $\geq 10^{3}$ atoms. Within the experimental uncertainties band III corresponds to the absorption of Xe atom in Ne matrix [37]. On the other hand, the absorption of Xe atom in surface sites (band I) only shows up for $<\mathrm{N}>\geq 300$. In the size range from $<\mathrm{N}>=40$ to 90 at./cluster an additional absorption band at higher energy side of the band III appears. It is labelled V. A similar band has not been observed in $\mathrm{XeAr}_{\mathrm{N}}$ and $\mathrm{XeKr}_{\mathrm{N}}$ clusters and it is a unique feature of $\mathrm{XeNe}_{\mathrm{N}}$ clusters.

These findings give strong evidence that small $\mathrm{XeNe}_{\mathrm{N}}$ clusters are liquidlike up to the size of $<\mathrm{N}>=200$. Moreover, a phase transition takes place for sizes between 200 and 300 at./cluster and the larger clusters become solid. According to calculations 
$10,0 \quad 10,2 \quad 10,4 \quad 10,6 \quad 10,8 \quad 10,0 \quad 10,2 \quad 10,4 \quad 10,6 \quad 10,8 \quad 11,0$

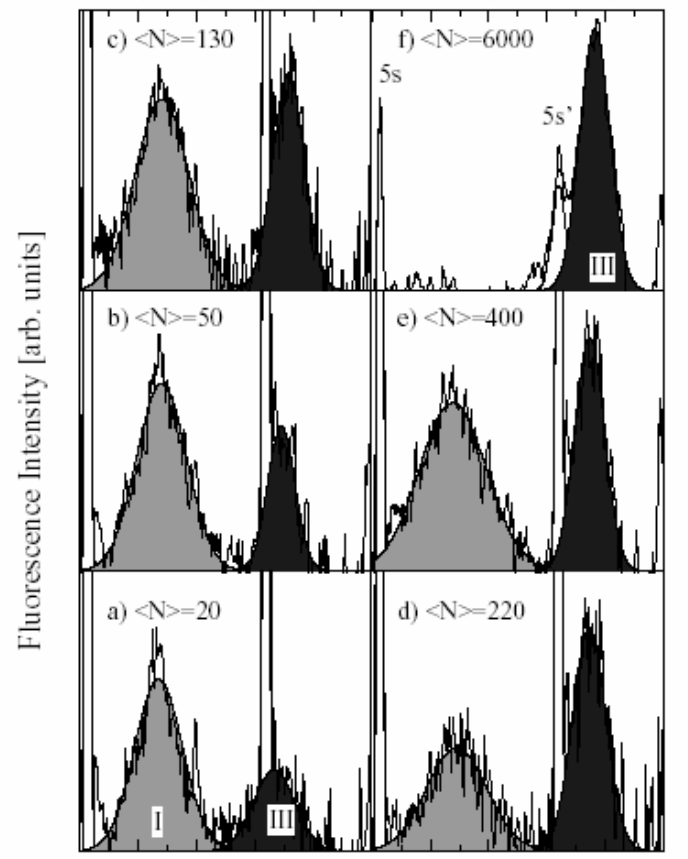

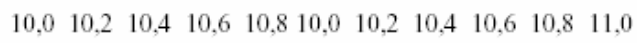

Excitation Energy [eV]

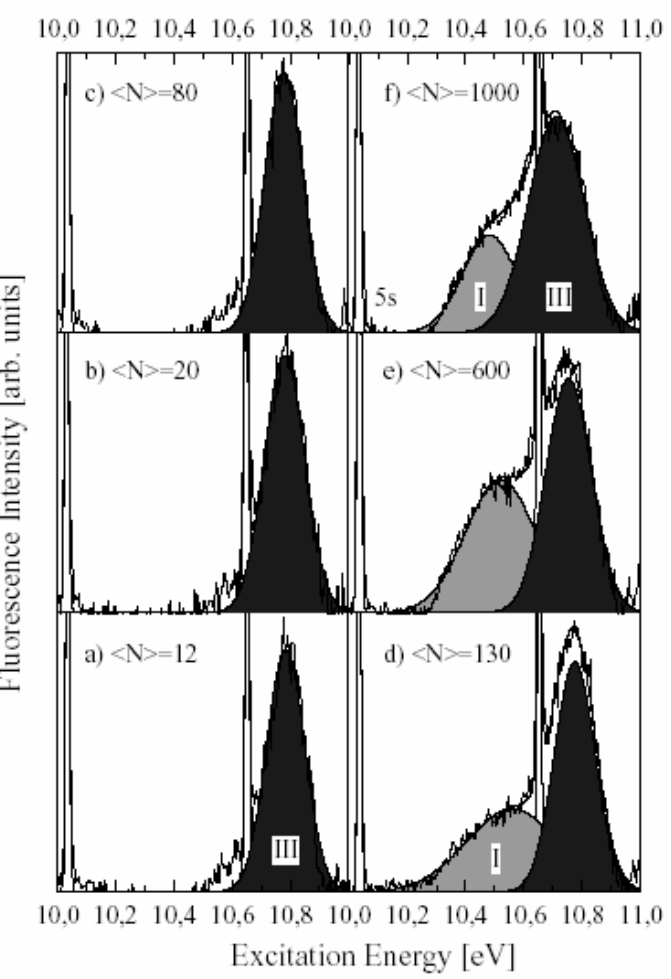

Fig. 9 Fluorescence excitation spectra of $\mathrm{KrNe}_{\mathrm{N}}$ clusters (coexpansion $0.003 \% \mathrm{Kr}$ in $\mathrm{Ne}$ ) for different cluster sizes $<\mathrm{N}>$.

very limited. The shift to high energy could be explained if one supposes either (1) an increased number or of the nearest neighbours or (2) that the distance to these neighbours decreases. The first supposition is not likely because the geometric limit of 18 neon atoms in the first shell is already attained for the bulk site responsible for band III. The second hypothesis looks more reasonable. In fact, partial compression of the bulk sites of clusters containing $40-90$ neon atoms is possible due to a large contribution to the cluster energetics of the surface energy. Moreover, the small neon clusters are liquid and their surface curvature is quite large. Surface tension may create a considerable pressure on the cluster interior. This additional force compresses $\mathrm{Xe}$ atom in the bulk sites leading to an increased spectral shift. In large clusters the surface curvature decreases and the band $\mathrm{V}$ disappears. The results of the band analysis are summarized in Table 4.

\subsection{5. $\mathrm{XeHe}_{\mathrm{N}}$}

He clusters differ considerably from the heavier rare gas clusters because they are liquid independently of their size. Moreover, in contrast to $\mathrm{XeAr}_{\mathrm{N}}, \mathrm{XeKr}_{\mathrm{N}}$ and $\mathrm{XeNe}_{\mathrm{N}}$ the doped He clusters cannot be produced by coexpansion of a gas mixture containing the impurity atoms. Indeed, the nozzle temperature as low as 10 $\mathrm{K}$ is needed to produce He clusters by adiabatic expansion [11]. In these conditions impurity atoms freeze at the nozzle. For this reason in current experiments $\mathrm{XeHe}_{\mathrm{N}}$ clusters have to be prepared by pick-up method. Moreover, the smallest clusters have to contain at least 1000 atoms to avoid the cluster evaporation in a collision with the impinging Xe atom. With more than thousand atoms the $\mathrm{He}$ cluster has enough heat capacity to accommodate the kinetic energy released on the impact.

Fluorescence excitation spectra of Xe-doped $\mathrm{He}_{\mathrm{N}}$ clusters for different sizes $<\mathrm{N}>$ are shown in Fig. 7. The spectra exhibit almost no size dependence in the size range from $<\mathrm{N}>=1000$ and up to $<\mathrm{N}>=10^{8}$. Only one absorption band at $8.9 \mathrm{eV}$ has 
Table 4 Results of analysis of $\mathrm{XeRg}_{\mathrm{N}}$ clusters $(\mathrm{Rg}=\mathrm{Kr}, \mathrm{Ne}, \mathrm{He}) .<\mathrm{r}_{\mathrm{NN}}>$ is obtained from the spectral shift of the corresponding bands using Eq. (2).

\begin{tabular}{|c|c|c|c|c|c|c|}
\hline \multirow{2}{*}{ Band } & \multicolumn{2}{|c|}{$\mathrm{Kr}$} & \multicolumn{2}{c|}{$\mathrm{Ne}$} & \multicolumn{2}{c|}{$\mathrm{He}$} \\
\cline { 2 - 7 } & $\Delta \mathrm{E}, \mathrm{meV}$ & $<\mathrm{r}_{\mathrm{NN}}>, \AA$ & $\Delta \mathrm{E}, \mathrm{meV}$ & $<\mathrm{r}_{\mathrm{NN}}>, \AA$ & $\Delta \mathrm{E}, \mathrm{meV}$ & $<\mathrm{r}_{\mathrm{NN}}>, \AA$ \\
\hline I & - & - & 380 & 3.90 & - & - \\
\hline Ia & 92 & 4.33 & - & - & - & - \\
\hline Ib & 170 & 4.28 & - & - & - & - \\
\hline II & 470 & 4.096 & - & - & - & - \\
\hline III & 543 & 4.060 & 688 & 3.77 & 453 & 4.13 \\
\hline V & - & - & 803 & 3.694 & - & - \\
\hline Rg2 & & $4.03^{\mathrm{a}}$ & & $3.03^{\mathrm{a}}$ & & $2.87^{\mathrm{a}}$ \\
\hline Rg solid & & $3.98^{\mathrm{a}}$ & & $3.16^{\mathrm{a}}$ & & $\sim 3.5$ \\
\hline Xe-Rg & & $4.20^{\mathrm{a}}$ & & $3.70^{\mathrm{a}}$ & & 3.7 \\
\hline
\end{tabular}

\section{${ }^{a}$ Ref. [35]}

been evidenced: its energy shift with respect to the free Xe-atom position and the spectral width amount respectively to $0.45 \pm 0.02$ $\mathrm{eV}$ to $0.195 \pm 0.007 \mathrm{eV}$. By analogy with the earlier considered systems this band has been assigned to $\mathrm{Xe}$ atom in the interior of liquid $\mathrm{He}$ cluster. This can be confirmed by estimation using Eq. (2). Indeed, Dalfovo [44] in his theoretical work has estimated the number of nearest neighbours for $\mathrm{Xe}$ impurities in liquid helium as $\mathrm{N}_{\mathrm{NN}}=23$ and the internuclear separation of Xe-He as $\mathrm{r}_{\mathrm{NN}}=4.2 \AA$. A slightly smaller value of $\mathrm{N}_{\mathrm{NN}}=22$ has been obtained in the MD-calculations in [43]. We will use this last value as a mean number of the nearest neighbours in helium clusters because the value given in [44] stands for a theoretical maximum. The measured energetic position of the absorption band III is in agreement with the theoretical prediction using the internuclear separation between $\mathrm{Xe}$ and $\mathrm{He}$ atoms of $4.13 \AA$, which is very close to the theoretical value of $4.2 \AA$ [44]. However, this value is slightly larger than that of the van der Waals minimum [35]. This is as expected because of the strong zero-point motion of He atoms. The results summarized in Table 4.

Additionally, it has been observed that the excitation spectra considerably shift to lower energies when the Xe crossjet pressure increases above some critical value. One possible explanation of this effect might be a heating of the He clusters due to the impact of more than one Xe atom, which increases the $\mathrm{Xe}-\mathrm{He}$ interatomic distance. According to Eq. (2) this would result in the red shift of the band. Another more realistic explanation of the observed energy shift could be the condensation of $\mathrm{Xe}$ atoms inside helium clusters. Massive condensation of Xe atoms can be observed by further increasing of the crossjet pressure and the size of the embedded $\mathrm{Xe}_{\mathrm{m}}$ clusters can attain $<\mathrm{N}>=200$ atoms in these experiments. This case will be discussed below in the section devoted to the multiple doped rare-gas clusters.

\subsection{6. $\mathrm{KrAr}_{\mathrm{N}}$ and $\mathrm{KrNe}_{\mathrm{N}}$}

In order to further establish our conclusions about the band identification, the above experiments were completed with doping of $\mathrm{Ar}_{\mathrm{N}}$ and $\mathrm{Ne}_{\mathrm{N}}$ clusters by $\mathrm{Kr}$ atoms. It is expected that the results are not specific to the nature of the impurity atom but rather to the properties of the solvated atom, because $\mathrm{Xe}$ and $\mathrm{Kr}$ are rather similar in their radius, mass or binding energy. As one can see in Fig. 8 and Fig. 9 the obtained spectra are indeed similar. Moreover, minor particularities can be explained by a general tendency in variation of the radius and binding energy of $\mathrm{Xe}$ and $\mathrm{Kr}$ atoms. Here we will only quantitatively discuss these results.

In $\operatorname{KrAr}_{\mathrm{N}}$ clusters (Fig. 8) two bands appear, which can be interpreted in terms of the surface and bulk substitutional sites occupied by $\mathrm{Kr}$ atom. The surface band dominates the absorption spectra of small clusters with $<\mathrm{N}>\leq 10^{2}$, while the absorption band from interior sites is more intense for larger clusters. The measured energy shift and using Eq. (2) allow identifying these bands respectively with the bands I and III, in terms applied for describing Xe-doped $\mathrm{Ar}_{\mathrm{N}}$ clusters. In contrast to Xe doping, of
$\mathrm{Ar}_{\mathrm{N}}$ clusters, the effect of the bulk site compression is considerably smaller. This is because $\mathrm{Kr}$ atom is smaller than $\mathrm{Xe}$ atom. Apparently, for this reason the band II (one layer below surface) merges into the band III and is not resolved in the excitation spectra.

$\mathrm{KrNe}_{\mathrm{N}}$ cluster spectra (Fig. 9) evolve with the size $\mathrm{N}$ in a similar way to that observed in $\mathrm{XeNe}_{\mathrm{N}}$ clusters. For small clusters only the interior site (band III) is present, while for larger clusters with $<\mathrm{N}>\geq 130$ the surface sites appear. The liquid-to-solid phase transition apparently takes place at a slightly lower cluster size as it has been observed with Xe doping: $\langle\mathrm{N}>\geq 300$. In contrast to $\mathrm{Xe}$, doping by $\mathrm{Kr}$ of $\mathrm{Ne}_{\mathrm{N}}$ clusters reveal no evidence for an additional band at the higher energy side of band III, which is due to the site compression (band V in Fig. 6). This is explained by the fact that $\mathrm{Kr}$ atom is smaller than $\mathrm{Xe}$ atom and weakly distorts the host neon lattice.

After the study of rare gas clusters doped with a single atom of the different compositions we have obtained a complete picture and detailed understanding of their formation with size.

\subsection{Small embedded $\mathrm{Rg}_{\mathrm{m}}$ clusters}

In this section we will discuss the impact of multiple doping on the fluorescence excitation spectra of rare-gas clusters. Multiple doping results in coalescence of atoms inside a large solvated $\operatorname{Rg}(1)_{\mathrm{N}}$ cluster and creation of small embedded rare-gas $\operatorname{Rg}(2)_{\mathrm{m}}$ clusters. We have considered experimental series with $\operatorname{Rg}(2)=\mathrm{Xe}, \mathrm{Kr}$ and $\mathrm{Ar}$ and $\operatorname{Rg}(1)=\mathrm{Ne}$ and He. Moreover, detailed studies of $\mathrm{Ar}_{\mathrm{m}} \mathrm{Ne}_{\mathrm{N}}$ and $\mathrm{Kr}_{\mathrm{m}} \mathrm{Ne}_{\mathrm{N}}$ clusters can be found in recent Refs [17] and [45]. The clusters were prepared by pick-up technique. Large $\mathrm{Ne}_{\mathrm{N}}$ and $\mathrm{He}_{\mathrm{N}}$ clusters $\left(<\mathrm{N}>>10^{3}\right)$ have been chosen as efficient solvated host clusters. As we observe, doping with many atoms results in the preparation of guest clusters inside host clusters. This is in contrast to single-atom-doping experiments discussed above, where surface sites are occupied in solid neon clusters of size $<\mathrm{N}>\geq 300$. In fact, doping of neon cluster by many atoms release a high amount of energy sufficient for the surface melting. Doping of surface sites in this case becomes inefficient and impurity atoms penetrate into the cluster interior.

We will see that the host cluster strongly influences the guest cluster electronic structure. In this case talking on size-effect we will mean the size $\mathrm{m}$ of the embedded cluster. These cluster-incluster samples allow studying of interface between two solids.

As we have mentioned in the previous section, when the atomic crossbeam pressure increases new absorption bands appear in the spectra. These bands can be assigned to rare-gas dimers and small clusters $\operatorname{Rg}_{m}(m \geq 3)$. The size of these embedded clusters is determined by the Poisson statistics. A special size calibration procedure based on comparison excitation lineshapes [28] allows estimating the mean size $\mathrm{m}$ of $\mathrm{Ar}_{\mathrm{m}}$ clusters inside large $\mathrm{Ne}_{\mathrm{N}}$ clusters as a function of the crossbeam pressure in a given experimental geometry. Replacement of $\mathrm{Ar}$ by $\mathrm{Xe}$ or $\mathrm{Kr}$ atoms does not change the doping conditions and the obtained calibration relation holds for all rare-gas atoms.

\subsection{1. $\mathrm{Xe}_{\mathrm{m}} \mathrm{Ne}_{\mathrm{N}}, \mathrm{Kr}_{\mathrm{m}} \mathrm{Ne}_{\mathrm{N}}$ and $\mathrm{Ar}_{\mathrm{m}} \mathrm{Ne}_{\mathrm{N}}$}

Fluorescent excitation spectra of large $\mathrm{Ne}_{7500}$ clusters doped with $\mathrm{Ar}_{\mathrm{m}}, \mathrm{Kr}_{\mathrm{m}}$ and $\mathrm{Xe}_{\mathrm{m}}$ clusters are shown in Fig. 10 for different sizes $\mathrm{m} \leq 10^{2}$.

Embedded $\mathrm{Ar}_{\mathrm{m}} \mathrm{Ne}_{\mathrm{N}}$ clusters in the total range of sizes exhibit 3 well-resolved absorption bands, which have been assigned to the bulk 1 't, $1^{\prime} 1$ and interface $1 \mathrm{i}(\mathrm{Ar}-\mathrm{Ne})$ excitons [17]. On the other hand, the surface 1s and 1's excitons are absent that indicate a perfect solvation of the $\mathrm{Ar}_{\mathrm{m}}$ cluster. As it is known, the volume excitons appear in free clusters when the second atomic shell is formed around the central atom, $m \geq 13$ [11-16]. Surface excitons share the cluster volume with the volume excitons and they are confined within a thin surface atomic layer. The experimental results explain its very small penetration depth into the cluster, typically $\delta_{1 \mathrm{~s}} \approx 0.8 \AA[18]$. A coexistence of the volume and interface excitons in our experiments indicates a very similar 

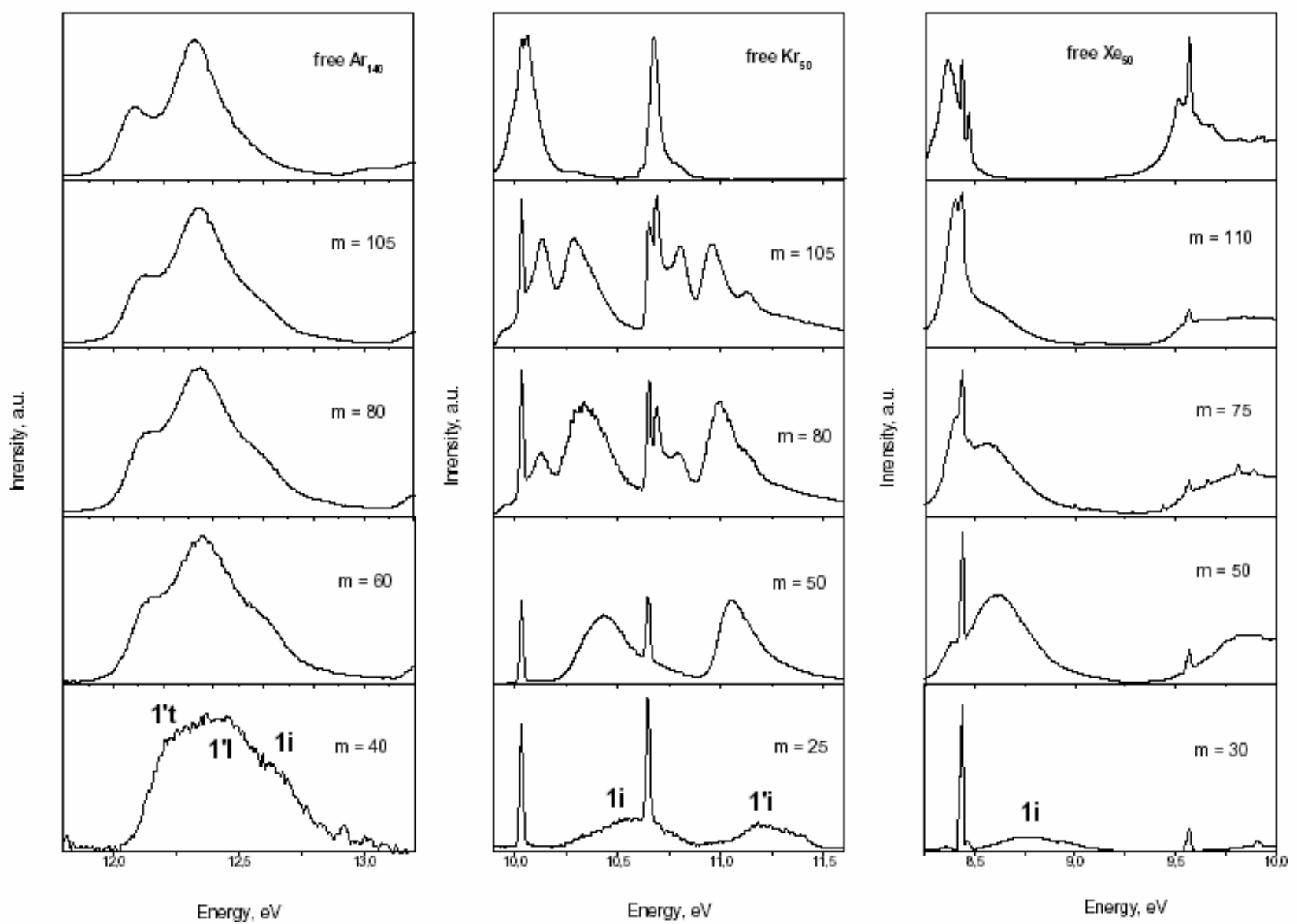

Fig. 10 Fluorescence excitation spectra of $\mathrm{Rg}_{\mathrm{m}} \mathrm{Ne}_{\mathrm{N}}$ clusters for different cluster sizes $\mathrm{m}(\mathrm{Rg}=\mathrm{Ar}, \mathrm{Kr}$, and $\mathrm{Xe})$. The sharp lines are due to atoms in the background gas.

formation of the electronic band structure of the solvated $\mathrm{Ar}_{\mathrm{m}}$ cluster to that of the free cluster. Moreover, detailed analysis of the spectral shift of the absorption bands with size m performed by Laarmann et al. [17] confirms this interpretation.

Indeed, as it has been shown in [17], this energy shift towards lower energy with increasing cluster can be understood in framework of the Frenkel exciton model taking the resonant excitation transfer into account. The resonant term expressed as

$$
\mathrm{L}_{\mathrm{f}}(\mathbf{k})=\sum \mathrm{M}_{\mathrm{np}}^{\mathrm{f}} \exp (\mathrm{ik}(\mathbf{n}-\mathbf{p}))
$$

dominates if excited atoms have no permanent dipole moment. Moreover, the matrix element $\mathrm{M}_{\mathrm{np}}^{\mathrm{f}}$ of the excitation transfer between atoms in positions with radius vectors $\mathbf{n}$ and $\mathbf{p}$ can be considered in the dipole-dipole approximation:

$$
\mathrm{M}_{\mathrm{np}}^{\mathrm{f}}=\left[\left(\mathbf{d}_{\mathrm{n}} \mathbf{d}_{\mathrm{p}}\right) \mathbf{r}_{\mathrm{np}}{ }^{2}-3\left(\mathbf{d}_{\mathrm{n}} \mathbf{r}_{\mathrm{np}}\right)\left(\mathbf{d}_{\mathrm{p}} \mathbf{r}_{\mathrm{np}}\right)\right] / \mathrm{r}_{\mathrm{np}}{ }^{5}
$$

where $d_{n}=d_{p}=d / \sqrt{\varepsilon}$ and is $\varepsilon$ the dielectric constant of the solid krypton. In this case the summation over all available excitation position in cluster of size $\mathrm{m}$ results in the expression for the energy shift [45]:

$$
\Delta \mathrm{E} \equiv \mathrm{L}_{\mathrm{f}}(\mathrm{m})=\mathrm{C}(\mathrm{R}, \delta) \int \rho(\mathrm{r}) / \mathrm{r}^{3} \mathrm{dV}
$$

where $\rho(r)=\exp (-(\mathrm{R}-\mathrm{r}) / \delta)$ is the density probability function of a surface (interface) exciton, $\delta$ is the penetration depth of the surface exciton inside the cluster and $\mathrm{C}(\mathrm{R}, \delta)$ is a normalization constant: $C(R, \delta) \int \rho(r) d V=1$. The integration in Eq. (3) is supposed to be carried out over entire cluster volume.

The fit of the energy shift versus the size $m$ of $\mathrm{Ar}_{\mathrm{m}} \mathrm{Ne}_{\mathrm{N}}$ clusters shows that it is linearly proportional to the number of the surface atoms and that the interface exciton penetration depth into the cluster volume is very small, $\delta_{\mathrm{Ar}-\mathrm{Ne}}<<\mathrm{r}(\mathrm{Ar}-\mathrm{Ar})$ [17].

However, the case of heavier $\mathrm{Kr}$ and $\mathrm{Xe}$ atoms is different. The small embedded clusters of these atoms display excitonic absorption spectra, which are not similar to that of the free clusters.
As we can see from Fig. 10, absorption bands due to excitons at the $\mathrm{Kr}-\mathrm{Ne}$ interface (1i and $1^{\prime} \mathrm{i}$ ) firstly appear and significantly shift to low energies with the increase of the cluster size $\mathrm{m}$. We remark that in agreement with the results of single atom doping, for small sizes $m \leq 10$ the cluster absorption band is situated at the position of the band III characteristic of the bulk position of $\mathrm{Kr}$ atom in $\mathrm{Ne}_{\mathrm{N}}$ clusters (see in Fig. 9). No band due to surface sites has been observed in these pick up experiments. The interface exciton bands shift towards lower energy with increasing of size of $\mathrm{Kr}$ cluster. The bulk excitons $\mathrm{n}=1,1^{\prime}$ of $\mathrm{Kr}_{m}$ clusters only appear in sufficiently large clusters with $\mathrm{m}>70$, where the third shell of atoms around the central $\mathrm{Kr}$ atom is under formation. This finding suggests a substantial particularity in the formation of the bulk solid electronic structure, which strongly depends on the cluster environment. Analysis of the spectra carried out in Ref. [45] shows that in small clusters the spectral shift of $1 i$ and 1 'i bands is proportional not to the number of surface atoms (as for $\mathrm{Ar}_{\mathrm{m}}$ ) but to the total number of $\mathrm{Kr}$ atoms $\mathrm{m}$ in the solute cluster. Moreover, the fit with Eq. (3) of the spectral shift results in a very large penetration of the interface exciton under the cluster surface: $\delta_{\mathrm{Kr}-\mathrm{Ne}} \approx 7.0 \pm 0.1 \AA$ [45]. This signifies that $\mathrm{Kr}$ atoms in the first and the second layers under the cluster surface participate in the resonance energy transfer. In contrast to the Ar$\mathrm{Ne}$ interface, the exciton at the $\mathrm{Kr}-\mathrm{Ne}$ interface expands into the $\mathrm{Kr}$ lattice over several interatomic distances.

The embedded $\mathrm{Xe}_{\mathrm{m}}$ clusters in $\mathrm{Ne}_{\mathrm{N}}$ clusters behave similar to that found in $\mathrm{Kr}_{\mathrm{m}}$ clusters (see in Fig. 10). They do exhibit interface exciton absorption bands, which dominate the spectra until the size $m \leq 70$. The interface excitations shift towards lower energy with increasing of the cluster size $\mathrm{m}$. Moreover, when the size $\mathrm{m}$ decreases they converge to the bulk band III position, characteristic of $\mathrm{XeNe}_{\mathrm{N}}$ clusters (see in Fig. 6). The fit of the experimental data of the spectral band shift with Eq. (3) results 


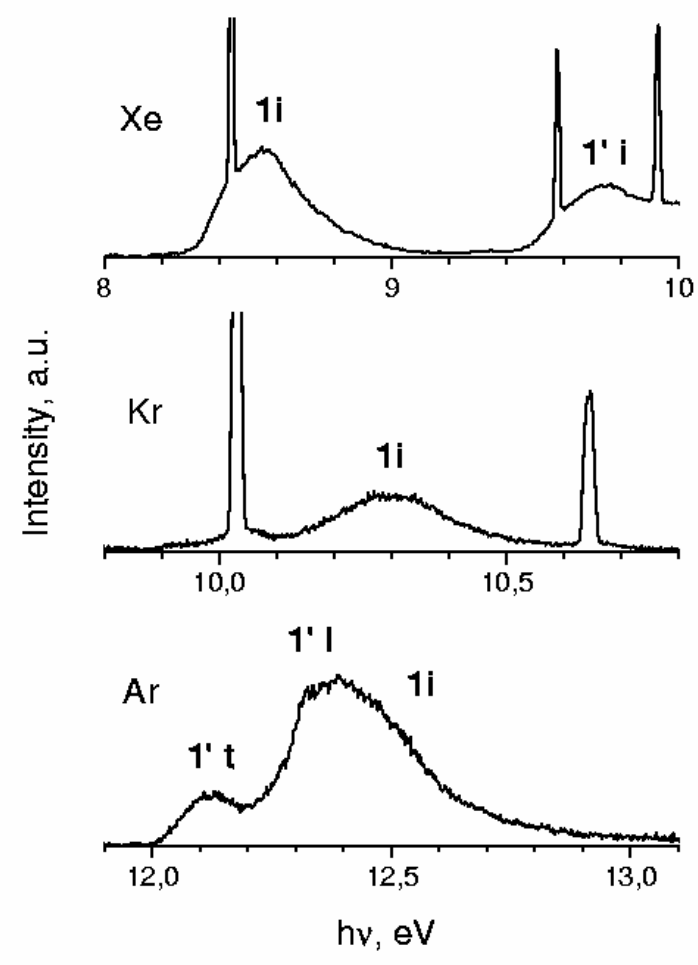

Fig. 11 Fluorescence excitation spectra of $\mathrm{Rg}_{\mathrm{m}} \mathrm{He}_{\mathrm{N}}$ clusters $(\mathrm{Rg}=\mathrm{Ar}, \mathrm{Kr}$ and $\mathrm{Xe},<\mathrm{N}>\approx 10^{4}$ ). The mean size of the embedded cluster is estimated as $m \approx 50$..

in the large penetration depth $\delta_{\mathrm{Xe}-\mathrm{Ne}} \approx 6.5 \pm 0.1 \AA$ of the $1 \mathrm{i}(\mathrm{Xe}-\mathrm{Ne})$ interface exciton into the $\mathrm{Xe}_{\mathrm{m}}$ cluster volume. This value is comparable to that obtained for the $\mathrm{Kr}-\mathrm{Ne}$ interface and considerably larger than that of the Ar-Ne interface.

\subsection{2. $\mathrm{Xe}_{\mathrm{m}} \mathrm{He}_{\mathrm{N}}, \mathrm{Kr}_{\mathrm{m}} \mathrm{He}_{\mathrm{N}}$ and $\mathrm{Ar}_{\mathrm{m}} \mathrm{He}_{\mathrm{N}}$}

The calibration procedure earlier tested for doping of neon clusters pick up method is not valid for helium clusters. Both the size of $\mathrm{He}_{\mathrm{N}}$ clusters and doping efficiency are delicate to determine, because the atom binding energy is very small and atoms easily leave the cluster after collisions with impurity atoms. Moreover, the cluster may be partially transparent that decreases the capture probability. As a result, we cannot give precise numbers for the size $m$ of the embedded clusters. For this reason the results of this section will be discussed qualitatively.

The examples of the excitation spectra of $\mathrm{Rg}_{\mathrm{m}} \mathrm{He}_{\mathrm{N}}$ clusters $(\mathrm{Rg}=\mathrm{Xe}, \mathrm{Kr}$ and $\mathrm{Ar}$ ) are presented in Fig. 11. These spectra have been measures with the atomic crossbeam pressure of 30 mbar. The means size of the host $\mathrm{He}_{\mathrm{N}}$ clusters in our nozzle expansion experiments has been estimated as $\sim 10^{4}$ at./cluster. Because the experimental geometry was almost conserved since the neon cluster series, we could also estimate the size of the embedded $\mathrm{Rg}_{\mathrm{m}}$ clusters. Within the error factor of 2 it amounts to $\mathrm{m} \approx 50$. As we can see, the general tendency observed in the doped $\mathrm{Ne}_{\mathrm{N}}$

Table 5 Electron affinities of rare-gas solids from Ref. [48]

\begin{tabular}{|c|c|c|c|c|c|}
\hline $\mathrm{Rg}$ & $\mathrm{Xe}$ & $\mathrm{Kr}$ & $\mathrm{Ar}$ & $\mathrm{Ne}$ & $\mathrm{He}$ \\
\hline $\mathrm{E}_{\mathrm{a}}, \mathrm{eV}$ & 0.4 & 0.3 & -0.4 & -1.3 & $<0^{a}$ \\
\hline$\delta_{\mathrm{Rg}-\mathrm{Ne}}, \AA$ & 6.5 & $7.0^{b}$ & $0.54^{c}$ & - & - \\
\hline $\begin{array}{c}\text { Bulk exciton in } \\
\mathrm{Rg}_{\mathrm{m} \leq 50 \mathrm{He}} \mathrm{He}_{\mathrm{N}}\end{array}$ & no & no & yes & - & - \\
\hline
\end{tabular}

" Because of strong repulsion forces, "bubble" is formed around the electron solvated in liquid helium. ${ }^{b}$ Ref. [45] ${ }^{c}$ Ref. [49] clusters is confirmed. The interface excitonic bands $1 \mathrm{i}$ have been observed in all clusters with sizes below $m \leq 100$. Moreover, while interface and bulk excitons coexist in $\mathrm{A}_{\mathrm{m} \leq 100} \mathrm{He}_{\mathrm{N}}$ clusters, only the interface excitons appear in $\mathrm{Xe}_{50} \mathrm{He}_{\mathrm{N}}$ and $\mathrm{Kr}_{50} \mathrm{He}_{\mathrm{N}}$ and smaller-m clusters.

\subsubsection{Comparison between $\operatorname{Rg}_{m} \mathrm{Ne}(\mathrm{He})_{\mathrm{N}}$ clusters} $(\mathrm{Rg}=\mathrm{Xe}, \mathrm{Kr}, \mathrm{Ar})$

Surface excitons of rare-gas solids $\operatorname{Rg}(\mathrm{s})$ are red-shifted in optical absorption spectra with respect to the bulk excitons because of larger binding energies. These excitons disappear when solids are covered by an atomic monolayer of different material [46]. This allows distinguishing them in the absorption spectra. When more than one atomic layer is deposited at the surface the interface between two solids is formed. In these conditions new interface excitons appear on the $\operatorname{Rg}(\mathrm{s})-\mathrm{A}$ interface $(\mathrm{A}=\mathrm{Rg})$, which are shifted to the blue from the bulk exciton position. This shift is due to a perturbation of the excited electronic orbital by the lighter rare-gas atoms A. Moreover, the complete electronic structure of $\operatorname{Rg}(\mathrm{s})$ could be perturbed. This electronic size effect has been recently a subject of our cluster studies [45], where an example $\mathrm{Kr}_{\mathrm{m}} \mathrm{Ne}_{\mathrm{N}}$ clusters has been considered. We have attributed this effect to different electron affinities between the two materials in contact. The observation of the electronic structure formation in different pairs of enclosed rare-gas clusters strongly support our recent conclusion.

The electron affinities $\mathrm{E}_{\mathrm{a}}$ of the rare-gas solids are listed in Table 5. As we see from it, $\mathrm{E}_{\mathrm{a}}$ values of heavy $\mathrm{Xe}$ and $\mathrm{Kr}$ solids are positive whereas that of lighter rare gases $\mathrm{Ar}, \mathrm{Ne}$ and $\mathrm{He}$ are negative. The sign and the value of electron affinity are determined by a balance between attractive polarization and short-range repulsion forces on the excess electron. In clusters the polarization forces weaken because of the excluded volume factor and the electron affinity decreases. It may even change the sign when the cluster size decreases, as theoretically proposed in Ref. [47] for $\mathrm{Kr}$ and $\mathrm{Xe}$.

The excited electron of rare-gases undergoes repulsion inside neon or helium clusters while attraction inside xenon or krypton ones. In this sense, a similarity exists between the additional solute electron and the remote one of the excited atom, and the electron affinity may play a key role in the understanding of build up of the cluster electronic structure. Because the electron affinity of the host cluster $(\mathrm{Ne}$ or $\mathrm{He}$ ) is negative, repulsion forces between $\mathrm{e}^{-}$and $\mathrm{Ne}(\mathrm{He})$ cluster apparently push the electron cloud of the interface exciton into the guest cluster volume with the positive value of $\mathrm{E}_{\mathrm{a}}$. In these conditions, the electronic structure of the embedded cluster has no signature of the bulk exciton until the penetration depth is larger than its cluster radius. If the electron affinity of both phases is negative, the interface exciton is localised in the uppermost layer of surface atoms of the embedded cluster, and the bulk exciton is formed as in free $\mathrm{Rg}_{\mathrm{m}}$ clusters.

A correlation between the sign of $\mathrm{E}_{\mathrm{a}}$ and the Rg-Ne interface exciton expansion under the cluster surface can be indeed seen from Table 5. As we see from it, the penetration depth $\delta$ is large in the embedded clusters with positive values of $\mathrm{E}_{\mathrm{a}}\left(\mathrm{Xe}_{\mathrm{m}}\right.$ and $\left.\mathrm{Kr}_{\mathrm{m}}\right)$. However, it is small in the embedded clusters with negative electron affinity $\left(\mathrm{Ar}_{\mathrm{m}}\right)$. Moreover, this tendency is confirmed in series of experiments with $\mathrm{Rg}_{\mathrm{m}} \mathrm{He}_{\mathrm{N}}$ clusters: the bulk excitons only appear in small clusters $(\mathrm{m} \leq 50)$ composed of Ar atoms.

\section{Conclusion}

In this work we have discussed a simple model for the explanation of the absorption spectra of rare-gas doped rare-gas clusters in the VUV spectral range. Two kinds of the samples have been studied: (i) $\mathrm{Rg}_{\mathrm{N}}$ clusters with single solute atoms at low doping rates and (ii) small $\mathrm{Rg}_{\mathrm{m} \leq 100}$ clusters embedded in large host clusters at high degree of doping. 
(i) All absorption bands that have been found were assigned using the theoretical model by Goldberg et al. [33] to three specific sites of the impurity atom at the cluster: surface sites, interior sites close below the surface and interior sites deep in the interior of the cluster. Moreover, a highly compressed site of the Xe-impurity atoms is evidenced in $\mathrm{Ne}_{\mathrm{N}}$ clusters for $40<\mathrm{N}<90$, which is a unique feature. It has been shown that the Xe impurity in the bulk substitutional sites of $\mathrm{Ar}$ and $\mathrm{Kr}$ clusters is compressed to fit into the cluster geometry: the internuclear Xe$\mathrm{Ar}$ and $\mathrm{Xe}-\mathrm{Kr}$ distances in the interior sites deep under the cluster surface approach the lattice constants of correspondent pure $\mathrm{Ar}$ or $\mathrm{Kr}$ solid. On the other hand, near or in the surface this compression does not appear in all considered doped clusters and the internuclear distances are found equal to that of the heteronuclear dimers. In soft neon and helium clusters respectively 18 and 22 cluster atoms assemble themselves around the Xe impurity. Moreover, analysis of the surface sites appearance allows to suppose that neon clusters of mean size below 200 are liquid-like and above 300 - solid. A phase transition takes place in this range of sizes.

(ii) We have found that small embedded $\mathrm{Rg}_{\mathrm{m}}$ clusters $(\mathrm{Rg}=\mathrm{Xe}$, $\mathrm{Kr}, \mathrm{Ar}$ ) of the size $\mathrm{m} \leq 10^{2}$ are formed in the interior sites of large host cluster made of $\mathrm{Ne}$ or He. Specific electronically excited states, assigned to the $\operatorname{Rg}(1)-\operatorname{Rg}(2)$ interface excitons have been observed. These absorption bands initially appear and shift towards lower energy when the embedded cluster size $\mathrm{m}$ increases. This behaviour is successfully described by the Frenkel exciton model taking the resonant energy transfer into account. The characteristic bulk excitons first appear in the spectra when the cluster radius exceeds some critical value of $\delta_{1 i}$, which is related to the interface exciton penetration depth. This value is sensitive to the electron affinities of the guest and the host clusters and can be considerably larger than that characteristic of free $\mathrm{Rg}_{\mathrm{N}}$ clusters. It is about two lattice constant for $(\mathrm{Xe}, \mathrm{Kr})-(\mathrm{Ne}, \mathrm{He})$ interfaces, where the electron affinities have opposite signs, whereas it is within one atomic layer at Ar$(\mathrm{Ne}, \mathrm{He})$ interfaces, where both electron affinities are negative. The method of analysing the absorption or fluorescence of impurity atoms in clusters has proven to be very promising for the understanding of electronic and geometric properties of these systems. Based on the experimental results of various combinations of materials, a detailed understanding of electronic structures and excited states in clusters could be obtained.

\section{Acknowledgments}

One of the authors (TM) is grateful to J. Jortner for many stimulating discussions. This work has been supported by the IHP-Contract HPRI-CT-1999-00040 of the European Commission.

\section{References}

1. H. Haberland, Clusters of Atoms and Molecules, vol. I (Berlin, Springer, 1993).

2. J. Jortner, Z. Phys. D 24, 247 (1992).

3. F. G. Amar, D. Levandier, L. Perera, and G. Scoles, in: Clusters of Atoms and Molecules, vol. II, edited by H. Haberland (Berlin, Springer, 1994), p. 19.

4. J. Bösiger, and S. Leutwyler, Phys. Rev. Lett., 59, 1895 (1987).

5. R. von Pietrowski, M. Rutzen, K. von Haeften, S. Kakar, and T. Möller, Z. Phys. D 40, 22 (1997).

6. M. Hartmann, R. E. Miller, J. P. Toennies, and A. Vilesov, Phys. Rev. Lett. 75, 1566 (1995).

7. R. Feifel, M. Tchaplyguine, G. Öhrwall, M. Salonen, M. Lundwall, R. R. T. Marinho, M. Gisselbrecht, S. L. Sorensen, A. Naves de Brito, L. Karlsson, N. Martensson, S. Svensson, O. Björneholm, Eur. Phys. J. D 30, 343 (2004).

8. D. Scharf, J. Jortner, and U. Landman, J. Chem. Phys. 88, 4273 (1988).

9. M. Lengen, M. Joppien, R. Müller, J. Wörmer, and T. Möller, Phys. Rev. Lett. 68, 2362 (1992).
10. M. Lengen, M. Joppien, R. von Pietrowski and T. Möller, Chem. Phys. Lett. 229, 362 (1994).

11. M. Joppien, R. Karnbach, and T. Möller, Phys. Rev. Letts. 71, 2654 (1993).

12. M. Joppien, Ph.D. thesis, Universität Hamburg, 1994.

13. J. Wörmer, M. Joppien, G. Zimmerer, and T. Möller, Phys. Rev. Lett. 67, 2053 (1991).

14. J. Stapelfeldt, J. Wörmer, and T. Möller, Phys. Rev. Lett. 62, 98 (1989).

15. J. Wörmer, V. Guzielski, J. Stapelfeldt, and T. Möller, Chem. Phys. Lett. 159, 321 (1989).

16. J. Wörmer, R. Karnbach, M. Joppien, and T. Möller, J. Chem. Phys. 104, 8269 (1996).

17. T. Laarmann, K. von Haeften, A. Kanaev, H. Wabnitz, and T. Möller, Phys. Rev. B 66, 205407 (2002).

18. J. Wörmer and T. Möller, Z. Phys. D 20, 39 (1991).

19. T. Laarmann, K. von Haeften, H. Wabnitz, and T. Möller, J. Chem. Phys. 118, 3043 (2003).

20. J. Farges, M. F. De Feraudy, B. Raoult, and G. Torchet, Surf. Sci. 106, 95 (1981).

21. J. P. Toennies, and A. F. Vilesov, Annu. Rev. Phys. Chem. 49, 1 (1998).

22. H. Wilke, W. Böhmer, R. Haensel and N. Schwenter, Nucl. Instr. Meth. 208, 59 (1983).

23. R. Karnbach, M. Joppien, J. Wörmer and T. Möller, Rev. Sci. Instr. 64, 10. (1993)

24. O.F. Hagena, W. Obert, J. Chem. Phys. 56, 5 (1979).

25. O. F. Hagena, Z. Phys. D 4, 291 (1987).

26. U. Buck and R. Krohne, J. Chem. Phys. 105, 5408 (1996).

27. C-R. Wang, R-B. Huang, Z-Y. Liu, L-S. Zheng, Chem. Phys. Lett. 227, 103 (1994).

28. A. Kanaev, L. Museur, F. Edery, T. Laarmann and T. Möller, J. Chem. Phys. 117, 9423 (2002).

29. M. Lewerenz, B. Schilling, and J. P. Toennies, J. Chem. Phys. 102, 8191 (1995).

30. T. L. Beck, J. Jellinek, R. S. Berry, J. Chem. Phys. 87, 545 (1987).

31. T. L. Beck, R. S. Berry, J. Chem. Phys. 88, 3910 (1988).

32. T. L. Beck, J. D. Doll, D. L. Freeman, J. Chem. Phys. 90, 5651 (1989).

33. A. Goldberg, A. Heidenreich, J. Jortner, J. Phys. Chem. 99, 2663 (1995).

34. A. Goldberg, J. Jortner, J. Chem. Phys., 107, 8994 (1997).

35. I. Y. Fugol, Adv. Phys. 27, 1 (1978).

36. I. Messing, B. Raz, J. Jortner, J. Chem. Phys. 66, 4577 (1977).

37. H. D. Lagier, K. H. Gödderz, J. Hormes, A. Klein, J. Molec. Struc. 222, (1990).

38. Wang, Y., Herron, N., Phys. Rev. B 42, 7253 (1990).

39. L. Perera, F. G. Amar, J. Chem. Phys. 93, 4884 (1990).

40. W. Laasch, Ph.D. thesis Universität Hamburg, 1992.

41. R. von Pietrowski, M. Lengen, L. Moussavizadeh, L. Museur, A. V. Kanaev, M. C. Castex, T. Möller, Faraday Discuss. 108, 175 (1997).

42. P. Slavicek, P. Jungwirth, M. Lewerenz, N. H. Nahler, M. Farnik, U. Buck, J. Phys. Chem. A 107, 7743 (2003).

43. R. von Pietrowski, Ph.D. thesis, Universität Hamburg, 1997.

44. F. Dalfovo, Z. Phys. D 29, 61 (1994).

45. A. Kanaev, L. Museur, F. Edery, T. Laarmann and T. Möller, Phys. Rev. B 69, 125343 (2004).

46. N. Schwentner, E.-E. Koch, and J. Jortner, Electronic Excitations in Condensed Rare Gases, Springer tracts in modern physics, vol. 107 (Springer, Berlin, 1985).

47. P. Stampfli and K.H. Bennemann, Phys. Rev. A 38, 4431 (1988).

48. M. Runne, J. Becker, W. Laasch, D. Varding, G. Zimmerer, Nucl. Instr. Meth. B 82, 301 (1993).

49. T. Laarmann, Ph.D. thesis, Universität Hamburg, 2001. 
